J. Dairy Sci. 101:5670-5670

https://doi.org/10.3168/jds.2018-101-6-5670

(๑) American Dairy Science Association ${ }^{\circledR}, 2018$.

\title{
Corrigendum to "Effect of inhibiting the lactogenic signal at calving on milk production and metabolic and immune perturbations in dairy cows" (J. Dairy Sci. 100:5782-5791)
}

N. Vanacker, S. Ollier, F. Beaudoin, R. Blouin, and P. Lacasse

On page 5787, the units for calcium concentration in panel $\mathrm{D}$ were incorrect. The correct unit is $\mathrm{n} M$. The corrected panel D of Figure 3 is shown below.

The authors regret the error.

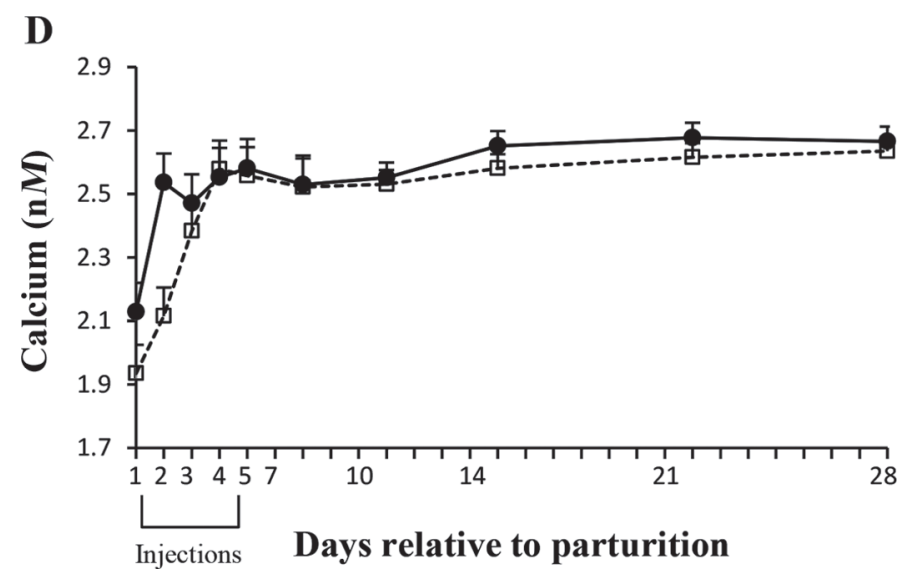

Figure 3. Blood concentrations of (A) BHB, (B) glucose, (C) nonesterified fatty acids (NEFA), and (D) calcium in cows that received 8 i.m. injections of either quinagolide (QUIN, $2 \mathrm{mg} ; \mathrm{n}=11$; $\bullet$ ) or water (control, CTL; $\mathrm{n}=11 ; \square$ ), with the first injection just after calving and subsequent injections every $12 \mathrm{~h}$. Data presented are LSM \pm SEM.

\section{REFERENCES}

Vanacker, N., S. Ollier, F. Beaudoin, R. Blouin, and P. Lacasse. 2017. Effect of inhibiting the lactogenic signal at calving on milk production and metabolic and immune perturbations in dairy cows. J. Dairy Sci. 100(7):5782-5791. https://doi.org/10.3168/jds.2017-12570. 